\title{
Metataxonomic analysis of tissue-associated microbiota in grooved carpet-shell (Ruditapes decussatus) and Manila (Ruditapes philippinarum) clams
}

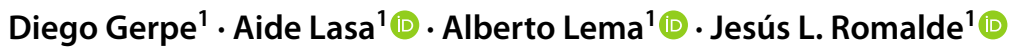

Received: 15 July 2021 / Revised: 17 September 2021 / Accepted: 21 September 2021 / Published online: 4 October 2021

(C) The Author(s) 2021

\begin{abstract}
Culture-dependent techniques only permit the study of a low percentage of the microbiota diversity in the environment. The introduction of next generation sequencing (NGS) technologies shed light into this hidden microbial world, providing a better knowledge on the general microbiota and, specifically, on the microbial populations of clams. Tissue-associated microbiota of Ruditapes decussatus and Ruditapes philippinarum (mantle, gills, gonad and hepatopancreas) was analysed in two different locations of Galicia (northwest of Spain) during Spring (April) and Autumn (October), employing a metataxonomic approach. High bacterial diversity and richness were found in all samples where a total of 22,044 OTUs were obtained. In most samples, phylum Proteobacteria was most frequently retrieved, although other phyla as Actinobacteria, Bacteroidetes, Tenericutes, Firmicutes or Chlamydiae also appeared at high relative abundances in the samples. At genus level, great variation was found across tissues and sampling periods. A Nonmetric Multidimensional Scaling (NMDS) and a hierarchical clustering analysis allowed to further analyse the factors responsible for the differences among groups of samples in the different sites. Results showed sample ordination based on tissue origin and sampling periods, pointing out that the microbiota was influenced by these factors. Indeed, predominance of certain genera was observed, such as Endozoicomonas or Methylobacterium in gills and gonads, respectively, suggesting that selection of specific bacterial taxa is likely to occur. So far, this study provided a general picture of the tissue associated microbial population structure in $R$. decussatus and $R$. philippinarum clams, which, ultimately, allowed the identification of specific tissue-related taxa.
\end{abstract}

Keywords Clams $\cdot$ Microbiota $\cdot$ Tissue associated $\cdot$ Population structure $\cdot$ Seasonality

\section{Introduction}

The culture of shellfish, specially clams and mussels, represents a key economic activity in the aquaculture of Galicia, a region in the North West of Spain. The overexploitation of natural beds led to the introduction of seeds and adult specimens from other countries, increasing the risk of introducing new bacterial pathogens that might disrupt the natural microbiota of the coastal environment, as well as the

Diego Gerpe and Aide Lasa contributed equally to this work.

Jesús L. Romalde

jesus.romalde@usc.es

1 Departamento de Microbiología Y Parasitología, CRETUS \& CIBUS-Facultad de Biología, Universidade de Santiago de Compostela, Campus Vida s/n, 15782 Santiago de Compostela, Spain microbial communities associated to marine organisms, such as molluscs (Bower et al. 1994).

Bivalve molluscs are powerful filter feeding organisms, allowed to filter large volumes of water, while concentrating different microorganisms. Bivalves, such as clams, are capable of retaining an important bacterial fraction in their organism, namely associated microbiota, while expelling to the environment the so-called microbiota in transition. Symbiotic associations, as a result of complex interactions, between bacteria and molluscs are well documented after selection upon the great marine microbial diversity (Mandel and Dunn 2016; Yu et al. 2019). Indeed, environmental microbiome play an important role in the formation and structure of the host-microbe complex (Singh et al. 2020). The associated microbiota plays different roles in bivalve molluscs, some of which may be beneficial for the host while others may have harmful effects (McHenery and Birkbeck 
1985; Prieur et al. 1990; Seguineau et al. 1996; Romalde et al. 2013, 2014).

Some studies focused on microbial communities in molluscs have analysed the variation of the bacterial population structure taking into account spatial (Colwell and Liston 1961; Colwell and Sparks 1967; Lovelace et al. 1968) and temporal variables (Pujalte et al. 1999), different phases of growth of the bivalve or the different composition of the microbiota in their organs (Rajagolapan and Sivalingan 1978). Most studies regarding microbiota of bivalve molluscs were based on the culturable fraction of bacteria and on the detection of pathogenic species (Paillard et al. 2004; Romanenko et al. 2008; Balboa et al. 2016). Recently, NextGeneration Sequencing (NGS) technologies have been introduced in the studies of the microbiota associated to different bivalve species, showing the high bacterial diversity present in the studied mollusc species. Some of these studies have focused on the analysis of whole-body homogenates (Trabal Fernández et al. 2014), single tissues (Lokmer and Wegner 2015; Roterman et al. 2015; Lasa et al. 2016) or compared the microbiota composition between different tissues (Lokmer et al. 2016; Vezzulli et al. 2017).

A study focused on oyster microbiota (Crassostrea corteziensis, Crassostrea gigas and Crassostrea sikamea) revealed a complex community consisting of 13 phyla and 243 genera associated with these molluscs in different life stages, where Proteobacteria was the predominant phylum in all stages. In postlarvae, the most relative abundant genera were Neptunibacter, Marinicella, Rhodovulum and Oceanicola, while in adults the dominant genera were Burkholderia and Escherichia-Shigella (Trabal Fernández et al. 2014). Other study based on the microbiota associated to Pecten maximus gonads (Lasa et al. 2016) had similar results and described 13 phyla and 110 genera, including Delftia, Acinetobacter, Hydrotalea, Aquabacterium, Bacillus, Sediminibacterium, Sphingomonas and Pseudomonas, as the most relative abundant taxa. More recently, a study conducted on the haemolymph and digestive gland microbiota of Mytilus galloprovincialis and C. gigas also revealed the predominance of phylum Proteobacteria, being Vibrio and Pseudoalteromonas the most retrieved genera in both bivalve species (Vezzulli et al. 2017).

Grooved carpet shell clam (Ruditapes decussatus) and Manila clam (Ruditapes philippinarum) are the more important reared clam species in Spain. So far, studies analysing the associated microbiota of these two species were focused in the culturable bacteria where the predominant genera were Vibrio and Pseudoalteromonas (Romalde et al. 2013; Leite et al. 2017).

In the present study, a metataxonomic analysis was performed on two different clam species, $R$. decussatus and R. philippinarum, gathered in Spring and Autumn in two different sites in the Galician coast (Redondela and Carril) to unravel the tissue-associated microbial population structure.

\section{Materials and methods}

\section{Sample collection}

Two different species of reared clams ( $R$. decussatus and $R$. philippinarum) were selected to analyse the associated microbiota to the different tissues (gonad, hepatopancreas, gills and mantle). The specimens ( $n=25$ of each species) were collected in site A $\left(42^{\circ} 36^{\prime} 50.4^{\prime \prime} \mathrm{N} 8^{\circ} 46^{\prime} 39.1^{\prime \prime} \mathrm{W}\right)$ and site B $\left(42^{\circ} 17^{\prime} 40.4^{\prime \prime} \mathrm{N} 8^{\circ} 36^{\prime} 57.2^{\prime \prime} \mathrm{W}\right)$ and in two different periods, Spring (April) and Autumn (October) (Fig. 1). In Spring, the registered water temperature was $13{ }^{\circ} \mathrm{C}$ in site A and $13.7^{\circ} \mathrm{C}$ in site $\mathrm{B}$, while in Autumn temperature of the water was $15.2{ }^{\circ} \mathrm{C}$ in site $\mathrm{A}$ and $16.5^{\circ} \mathrm{C}$ in site B. Immediately after collection, clam samples were transported to the laboratory in a refrigerator at $4{ }^{\circ} \mathrm{C}$, approximately during $3 \mathrm{~h}$.

\section{Tissue homogenization}

The clams were aseptically opened for the extraction of the tissues (gonad, hepatopancreas, gills and mantle) using a sterile scalpel. Then, each tissue from the 25 specimens was pooled and homogenized in PBS. Briefly, bacterial cells of each sample were separated from eukaryotic cells and concentrated using a gradient centrifugation. This gradient was performed using OptiPrep ${ }^{\mathrm{TM}}$ (Sigma), a medium of gradient density composed of $60 \%$ of iodinaxol. OptiPrep ${ }^{\mathrm{TM}}$ was diluted with $0.25 \mathrm{M}$ sucrose, $6 \mathrm{mM}$ EDTA, $60 \mathrm{mM}$ Tris- $\mathrm{HCl}, \mathrm{pH} 7.4$ to produce $14 \%, 25 \%$ and $55 \%$ (w/v) iodixanol. Four millilitres of each concentration of iodixanol was layered, and $10 \mathrm{ml}$ of each sample was layered on top. A first centrifugation was made at $3.800 \times \mathrm{g}$ at $4-10^{\circ} \mathrm{C}$ for $60 \mathrm{~min}$. Then, the upper layer was collected in other tube and centrifuged again at $3000 \times \mathrm{g}$ at $4{ }^{\circ} \mathrm{C}$ for $60 \mathrm{~min}$. The pellet was washed with $2 \mathrm{ml}$ of PBS by centrifugation and centrifuged during $30 \mathrm{~min}$ at $13,000 \times \mathrm{g}$. Finally, the pellet was resuspended in $1 \mathrm{ml}$ of PBS and stored at $-20^{\circ} \mathrm{C}$ until DNA extraction.

\section{DNA extraction and PCR amplification}

DNA was extracted using the MasterPure Complete DNA and RNA Purification kit (Epicentre Biotechnologies) following the manufacturer's instructions. DNA concentration and quality were determined by agarose gel electrophoresis (1\% wt/ vol agarose in Trisacetate-EDTA buffer) and using NanoDrop ND-1000 spectrophotometer (Thermo Scientific). Extracted DNA was stored at $-20{ }^{\circ} \mathrm{C}$ until use for PCR amplification. 
Fig. 1 Geographical map of Galicia (NW Spain) showing the two selected sampling sites. Source of colour pictures: Google Earth (data accession July $12^{\text {th }}, 2021$ )

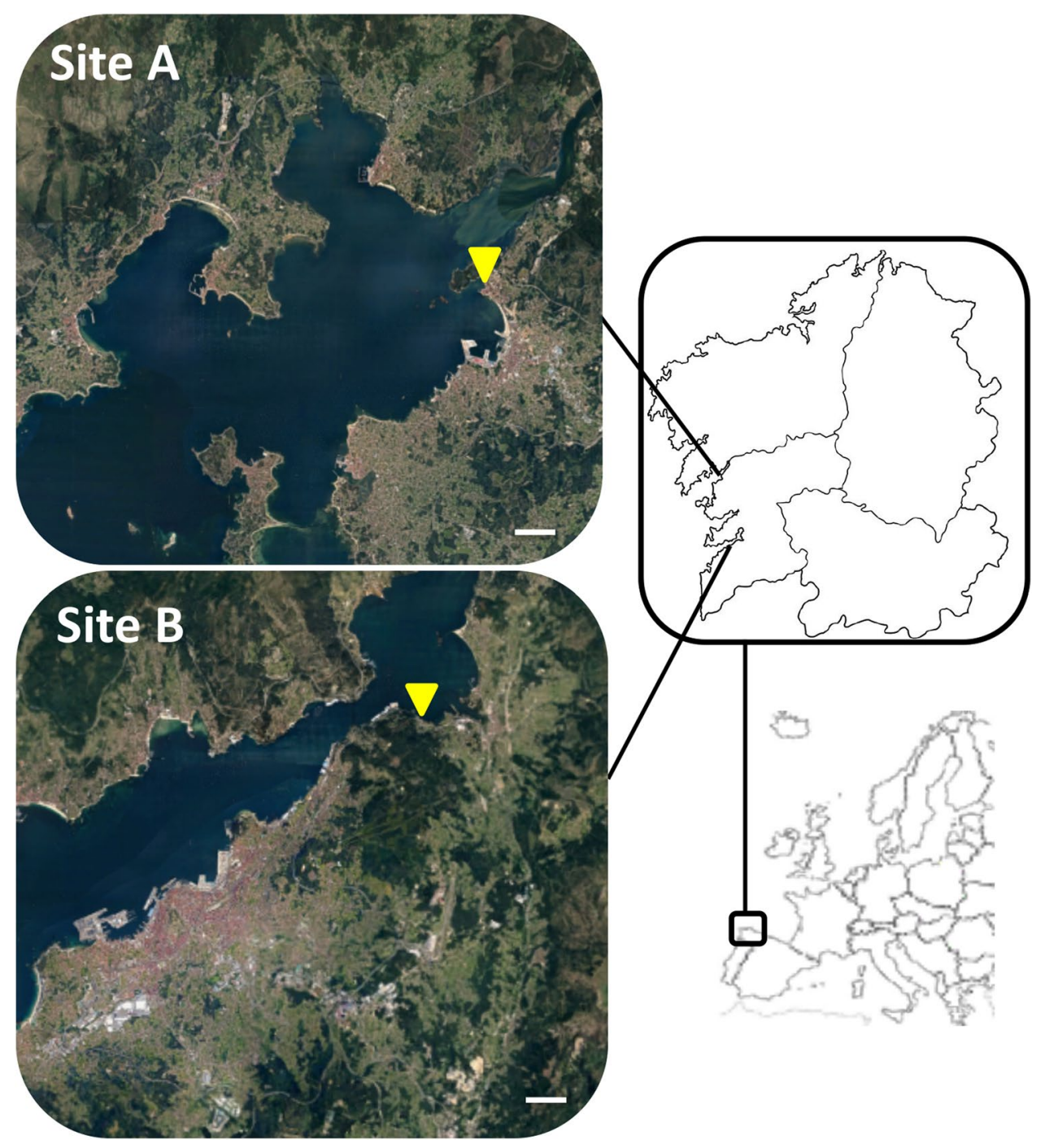

Genomic DNA from each sample was used for the amplification of 16S rRNA gene using primers targeting the hypervariable regions V3/V4 (Lee et al. 2012): 338F (5'- TCGTCG GCAGCGTCAGATGTGTATAAGAGACAGACTCCTACG GGAGGCAGCA-3') and 806R (5'GTCTCGTGGGCTCGG AGATGTGTATAAGAGACAGGGACTACHVGGGTWT CTAAT-3'). Sterilized MilliQ water was included as a negative control. The $16 \mathrm{~S}$ rRNA amplicons were verified by gel electrophoresis on a $2 \%$ agarose gel using GreenSafe DirectLoad (NZytech) for the staining. DNA concentration was determined using a NanoDrop ND-1000 spectrophotometer (Thermo Scientific).

\section{S rRNA amplicon sequencing and data analysis}

16S amplicons were sequenced at Sistemas Genómicos (Valencia, Spain) using Illumina MiSeq platform, generating paired-end $2 \times 250$ bp reads.

Illumina reads were analysed for quality control using FastQC software (Brabaham Bioinformatics). Quality trimming of reads was performed based on quality scores $(\mathrm{Q}<30)$ and length trimming (200 base pairs-bp), using Trimmomatic 0.32 (Bolger et al. 2014) program, as well as chimera detection and removal. The filtered paired-end reads were then merged using the command fastq-join (Quast et al. 2013) and clustered at $97 \%$ level of similarity into OTUs. Ribosomal RNA gene reads were classified 
against the non-redundant version of the SILVA SSU reference taxonomy (release 123; http://www.arb-silva.de). For bacterial diversity estimation in the samples, the number of operational taxonomic units (OTUs) at $97 \%$ sequence identity was determined, and rarefaction analyses were carried out. Briefly, the reads were aligned against the 16S rRNA sequences of the SILVA database followed by a quality filtering including length, ambiguity and homopolymer checks. A de-replication step was performed to collapse identical reads into one single sequence, and OTUs were clustered at $3 \%$ divergence threshold. The mitochondria, chloroplasts and unassigned reads were deleted for the taxonomic analysis.

\section{Statistical analysis}

Nonmetric Multidimensional Scaling (NMDS), hierarchical clustering and analysis of similarities (ANOSIM) were performed from the dissimilarity matrix using vegan package of R (Clarke 1993, Oksanen et al. 2017). Heatmap was also performed using pheatmap package (v. 1.0.12, Kolde 2015).

Table 1 Summary of the characteristics of all samples of $R$. decussatus and $R$. philippinarum, sequences analysed and diversity/richness indexes

\begin{tabular}{|c|c|c|c|c|c|c|c|c|c|}
\hline Sample & Sampling period & Site & $\begin{array}{l}\text { Number of } \\
\text { sequences }\end{array}$ & Avg. length & OTUs & $\%$ classified & $\begin{array}{l}\text { Number of } \\
\text { sequences observed } \\
\text { once }\end{array}$ & $\begin{array}{l}\text { Number of } \\
\text { sequences observed } \\
\text { twice }\end{array}$ & Chao-1 \\
\hline ADM 1 & April & A & 6024 & 463 & 844 & 97.44 & 409 & 159 & 1365.48 \\
\hline ADG 1 & April & A & 8583 & 465 & 829 & 99.11 & 393 & 143 & 1363.92 \\
\hline ADGo 1 & April & A & 17,903 & 454 & 2549 & 98.91 & 1324 & 504 & 4283.31 \\
\hline ADHp 1 & April & A & 13,526 & 454 & 437 & 99.65 & 114 & 38 & 602.15 \\
\hline $\mathrm{ADM} 2$ & October & A & 9929 & 466 & 429 & 99.68 & 164 & 59 & 651.77 \\
\hline ADG 2 & October & A & 14,102 & 457 & 559 & 99.26 & 139 & 83 & 673.18 \\
\hline ADGo 2 & October & A & 29,734 & 460 & 1092 & 99.90 & 356 & 169 & 1463.71 \\
\hline ADHp 2 & October & A & 18,020 & 464 & 654 & 72.79 & 127 & 70 & 766.69 \\
\hline BDM 1 & April & B & 2532 & 462 & 381 & 94.08 & 227 & 51 & 874.29 \\
\hline BDG 1 & April & B & 2231 & 458 & 417 & 94.04 & 251 & 60 & 931.34 \\
\hline BDGo 1 & April & B & 5105 & 458 & 861 & 97.90 & 378 & 190 & 1234.05 \\
\hline BDHp 1 & April & B & 19,036 & 460 & 2455 & 97.53 & 902 & 469 & 3319.58 \\
\hline BDM 2 & October & B & 3251 & 459 & 379 & 99.14 & 178 & 67 & 610.66 \\
\hline BDG 2 & October & B & 12,018 & 457 & 639 & 99.60 & 179 & 91 & 812.16 \\
\hline BDGo 2 & October & B & 21,290 & 451 & 1108 & 99.50 & 284 & 159 & 1359.16 \\
\hline BDHp 2 & October & B & 18,994 & 451 & 565 & 99.58 & 151 & 53 & 774.72 \\
\hline APM 1 & April & A & 7340 & 462 & 599 & 98.83 & 178 & 93 & 766.59 \\
\hline APG 1 & April & A & 5462 & 462 & 522 & 72.28 & 245 & 103 & 809.40 \\
\hline APGo 1 & April & A & 26,402 & 457 & 1434 & 93.41 & 252 & 133 & 1670.01 \\
\hline APHp1 & April & A & 30,581 & 461 & 2042 & 99.36 & 441 & 284 & 2382.42 \\
\hline APM 2 & October & A & 3887 & 466 & 285 & 98.56 & 153 & 35 & 608.00 \\
\hline APG 2 & October & A & 22,202 & 462 & 982 & 99.63 & 272 & 108 & 1320.13 \\
\hline APGo 2 & October & A & 27,372 & 454 & 774 & 99.88 & 150 & 87 & 900.99 \\
\hline APHp 2 & October & A & 22,915 & 456 & 918 & 98.66 & 241 & 125 & 1147.52 \\
\hline BPM 1 & April & B & 1899 & 463 & 171 & 88.94 & 103 & 19 & 433.65 \\
\hline BPG 1 & April & B & 3912 & 465 & 350 & 68.71 & 178 & 49 & 665.06 \\
\hline BPGo 1 & April & B & 6003 & 456 & 706 & 98.23 & 246 & 129 & 937.81 \\
\hline ВРНp 1 & April & B & 24,009 & 460 & 1879 & 97.62 & 578 & 307 & 2420.41 \\
\hline ВРМ 2 & October & B & 5153 & 462 & 395 & 88.03 & 206 & 57 & 759.05 \\
\hline BPG 2 & October & B & 1738 & 464 & 240 & 47.01 & 147 & 36 & 530.03 \\
\hline BPGo 2 & October & B & 25,621 & 454 & 874 & 94.02 & 155 & 106 & 985.54 \\
\hline ВрНр 2 & October & B & 24,898 & 454 & 499 & 96.61 & 94 & 39 & 608.28 \\
\hline
\end{tabular}

A site A, $B$ site B, $D$ R. decussatus, $P$ R. philippinarum, $M$ mantle, $G$ gills, Go gonads, $H p$ hepatopancreas, 1 April, 2 October 


\section{Results}

After filtering raw sequences obtained from the V3/V4 region of 16S rRNA, a total of 441,672 reads were obtained from samples of $R$. decussatus and $R$. philippinarum with an average length from 453 to $460 \mathrm{pb}$. A total of 22,044 OTUs were obtained, of which more than $93 \%$ of clustered sequences could be taxonomically assigned (Table 1), except for samples ADHp1, APG1, BPG1 and BPG2. Rarefaction analysis (at 97\% sequence identity level) (Fig. 2) of $R$.

Fig. 2 Rarefaction analysis of samples of $R$. decussatus and $R$. philippinarum, showing the number of OTUs (at $97 \%$ 16S rRNA gene sequence identify) as a function of the number of sequences analysed. A site A, $\mathrm{B}$ site $\mathrm{B}, \mathrm{D} R$. decussatus, $\mathrm{P} R$. philippinarum, $\mathrm{M}$ mantle, $\mathrm{G}$ gills, Go gonads, Hp hepatopancreas, 1 April, 2 October
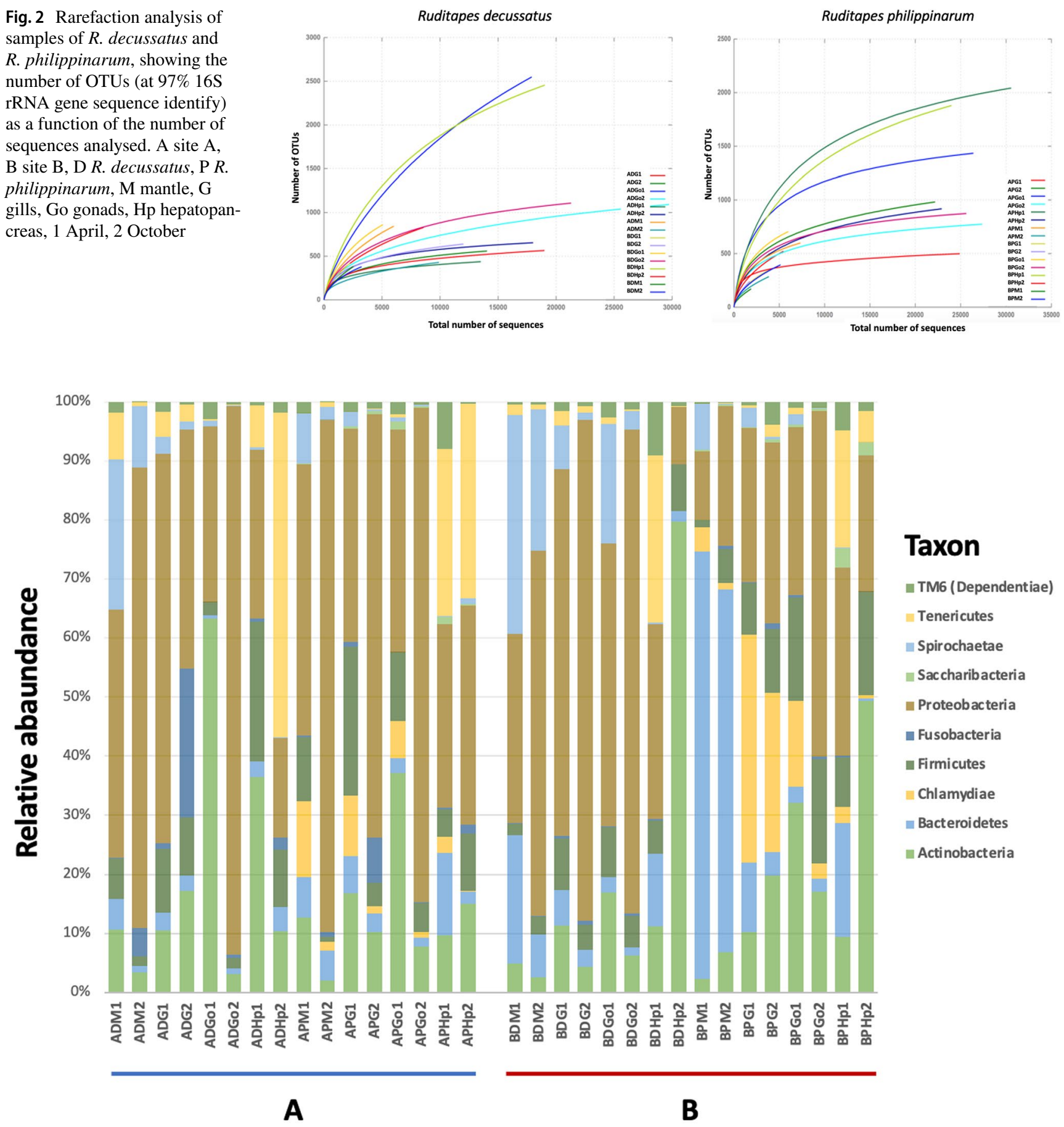

Fig. 3 Relative abundances of bacterial phyla associated to R. decussatus and $R$. philippinarum organs indicating sampling sites A and B. The graphic shows the percentages $(>1 \%)$ of the $16 \mathrm{~S}$ rRNA reads assigned to different bacteria taxa. A site A, B site B, D R. decussatus, $\mathrm{P}$ R. philippinarum, M mantle, G gills, Go gonads, Hp hepatopancreas, 1 April, 2 October 
decussatus and $R$. philippinarum samples showed that most samples reached saturation or asymptotic phase.

Taxonomic assignment of the sequences using the SILVAngs database identified more than 30 different phyla within the two clam species microbial communities. Despite the high number of phyla detected, more than $90 \%$ of the observed diversity can be explained taking into account only 14 phyla that dominated the total bacterial population (Fig. 3). Among them, Proteobacteria, Firmicutes, Actinobacteria, Bacteroidetes or Spirochaetae account for the major fraction on every sample, but displaying compositional variations depending on the tissue, sampling period or clam species. For instance, samples gathered in site A harboured, predominantly, bacteria belonging to Proteobacteria (ranging from 15.6 to $91.6 \%$ ) in both clam species. However, for samples ADGo1, ADHp1 and ADHp2, the major fraction of the bacterial population could be explained by Actinobacteria (58.4\% and 35.4\%) and Tenericutes (50.8\%) respectively (Fig. 3). On the other hand, samples taken in site $\mathrm{B}$ displayed different bacterial communities depending on the clam species and tissue. Grooved carpet-shell clams showed similar bacterial phyla composition to that in site A, composed by Proteobacteria mainly (ranging from 29.8 to $82.6 \%$ ), although the BDM1 sample showed a more diverse bacterial population formed by Spirochaetae (36.2\%), Proteobacteria (31.2\%) and Bacteroidetes (21.2\%). Manila clam samples from site B showed a different microbial population pattern, and Proteobacteria was the predominant phylum only in BPG2 (30.2\%), BPGo2 (57.1\%) and BPHp1 (29.4\%) samples. Conversely, mantle samples were enriched in phylum Bacteroidetes (71.9\% and 60.8\%), and the BPG1 sample was dominated by phylum Chlamydiae (37.8\%). Besides, BPGo1 and BPHp2 samples showed the predominance of Actinobacteria, $31.2 \%$ and $48.9 \%$ respectively (Fig. 3).

\section{Tissue specificity and seasonal variation}

16S rRNA amplicon analysis at the genus level showed distinct relative abundances across tissues in both clam species. Relative abundance differences observed in specific bacterial genera may indicate that selection of specific bacterial groups upon the great microbial diversity in the marine environment is likely to occur. For instance, Endozoicomonas genus appeared in gill samples of grooved carpet shell clams in both sites at high relative abundances, especially in sample ADG1 (43\%), while this genus was not detected or at very low concentrations $(<1 \%)$ in other tissues and $R$. philippinarum clams. Similarly, gonad samples from the two different clam species at both sites were enriched in Methylobacterium genus, representing 25.3\%, 39.1\%, 32.1\% or $30.5 \%$ in $\mathrm{ADGo} 2, \mathrm{APGo} 2, \mathrm{BDGo} 2$ and $\mathrm{BPGo} 2$ samples, respectively (Fig. 4).

Uncultured Microscillaceae was the predominant taxon in mantle samples of Manila clams from site B in both periods,
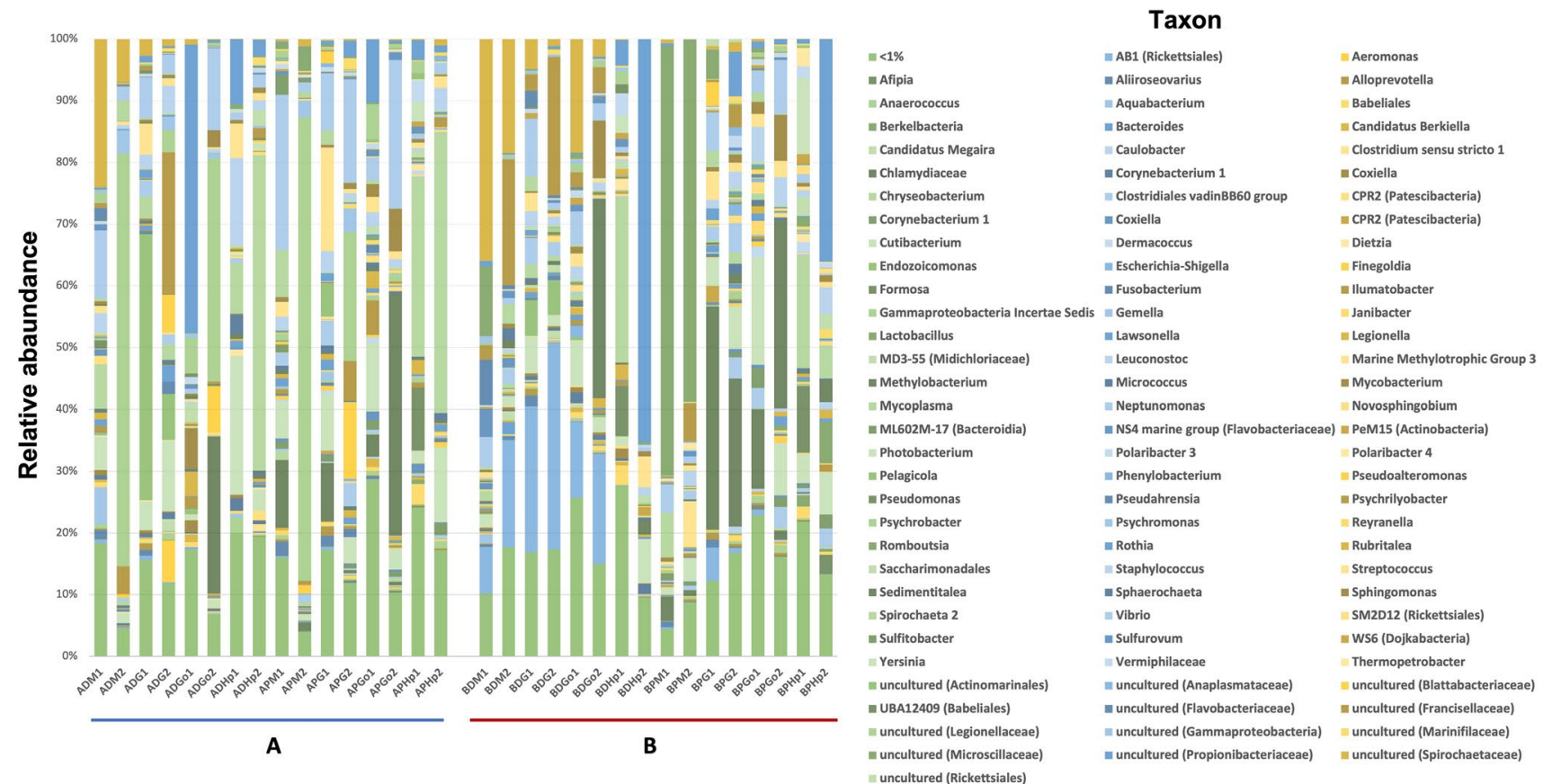

Fig. 4 Relative abundances of bacterial genera associated to R. decussatus and $R$. philippinarum organs indicating sampling sites $\mathrm{A}$ and B. The graphic shows the percentages $(>1 \%)$ of the $16 \mathrm{~S}$ rRNA reads assigned to different bacterial taxa. A site A, B site B, D R. decussatus, $\mathrm{P}$ R. philippinarum, M mantle, G gills, Go gonads, Hp hepatopancreas, 1 April, 2 October 
accounting for more than $59 \%$ of relative abundance. Conversely, grooved carpet shell clam samples from site B showed high concentrations of AB1 Rickettsiales (7.5 to $33.3 \%$ ) in all studied organs and sampling periods, except in hepatopancreas in which, this taxon, was not detected.

Uncultured Propionibacteriaceae were more related to gonad and hepatopancreas samples from site A during Spring (46.7 to $3.1 \%$ ) in both clam species, while in site $\mathrm{B}$ this group was predominately related to Hepatopancreas tissue during the second sampling period (65.2 to $35.4 \%$ ). Another genus detected specially in hepatopancreas samples is Mycoplasma. In site A, an increase was observed from Spring to October, from 8.1 to $51 \%$ (R. decussatus) and from 28.9 to $45.5 \%$ (R. phillipinarum). On the other hand, Mycoplasma was more abundant in hepatopancreas samples during Spring in site B.

Sampling period (Spring and Autumn) also influenced bacterial community structures associated to the different tissues. It is well known that water temperature shapes marine microbiota, and, as a consequence of their filterfeeding habit, clam microbiota is affected, too. This appears evident for the genus Psychrobacter in samples of mantle, gills and gonads from site $\mathrm{A}$, from both $R$. decussatus and $R$. philippinarum species, which relative abundances are increased during the second sampling period (Autumn). Similar trend is observed in Methylobacterium genus in which we observed an increase during Autumn period in gonad samples compared to Spring period. Conversely, Chlamydiaceae bacterial group resulted more abundant in Spring samples (APM1, APG1, APGo1, BPM1, BPG1 or BPGo1) than in Autumn samples.

These findings were confirmed when a hierarchical clustering of the most abundant genera ( $>5 \%$ relative abundance), separately in both sites, was performed. The resulting heatmap showed that genera correlated well with their association to tissues or the sampling period, as depicted in Fig. 5. In general, samples in site A belonging to the same organ clustered together except for samples ADHp1, APGo1, ADM1, APM1, APG1, which appear to be more affected by environmental factors. This is less evident in site $\mathrm{B}$, in which the sampling period seemed to be the responsible of the sample clustering. These results suggest that both variables are involved in defining the associated microbial communities in both clam species.

Microbial composition differences have been reflected, as well, when a Nonmetric Multidimensional Scaling (NMDS), applied on ANOSIM distance matrix, analysis was performed. This analysis led to further investigate the factors responsible for differences among group of samples in the different sites. In site A, samples appeared to be ordinated based on sampling period and tissue origin rather than on clam species (Fig. 6A), except hepatopancreas samples that were ordinated based on the clam species, although every sample was separated further apart one to each other. In contrast, site B samples were ordinated according to clam species and by organs, as well, except for hepatopancreas samples which were more similar between sampling periods (Fig. 6B). Gill and gonad samples clustered together, while hepatopancreas and mantle samples were clearly separated based on clam species and sampling period, respectively.

\section{Influence of habitat on clam microbiota}

When analysing the data obtained on the basis of the origin of sampling (A or B), it becomes clear that the environment of these two locations is playing an important role shaping the associated microbiota of $R$. decussatus and R. philippinarum clams. Differences at the genus level are evident when comparing the microbiota of the same clam species from different locations. For instance, in site B, grooved carpet shell clam displayed a stable relative abundance of $\mathrm{AB} 1$ Rickettsiales group throughout the different organs (except in hepatopancreas), while in site A this genus appears at low concentrations $(<1 \%)$ (Fig. 4). Similarly, genus Psychrobacter is mainly associated to $R$. decussatus and R. philippinarum clams in site A (Fig. 5) at high relative abundances, ranging from 20.6 to $75.5 \%$, (ADM2, APM2, ADGo2 or APG2), but in site B its presence is clearly reduced (lower than 1\%). Despite these differences, bacterial groups such as Methylobacterium or Endozoicomonas, which appear to be positively selected in gonad and gill samples respectively, seemed not to be affected by the different environments. Mantle and hepatopancreas bacterial populations displayed considerable differences between locations. Mantle and hepatopancreas in site B were enriched in uncultured Microscillaceae and uncultured Propionibacteriaceae taxa, while Psychrobacter and Mycoplasma were dominant in those tissues in site A location (Fig. 5A). Vibrios were also identified in all samples; however, their relative abundance was higher in site A, ranging from 25.9 to $0.8 \%$, while in site B their presence is clearly reduced, ranging from 9.3 to $0.4 \%$.

\section{Discussion}

In the present study, we investigated the organisation of the tissue-associated microbiota of Grooved carpet shell clam, $R$. decussatus, and Manila clam, $R$. philippinarum, in two different locations (A and B) and in two periods, Spring and Autumn. A considerable heterogeneity among individuals was demonstrated for other bivalves, such as pearl oyster (King et al. 2021). In our work, in order to get a solid overview of the bacterial communities associated with clam populations that could be useful for the determination of their sanitary status, pooled samples were employed to avoid possible microbial composition changes due to individual 
Fig. 5 Hierarchical clustering dendrogram of microbiota associated to clam tissues. The heatmap depicts the relative abundance of each genus in each sample applied on ANOSIM distance matrix. A Dendrogram of site A. B Dendogram of site B. The colour scale, tissue and sampling period for the heatmap is displayed in the right side of the figure. A site A, B site B, D R. decussatus, $\mathrm{P}$ R. philippinarum, $\mathrm{M}$ mantle, $\mathrm{G}$ gills, Go gonads, Hp hepatopancreas, 1 April, 2 October
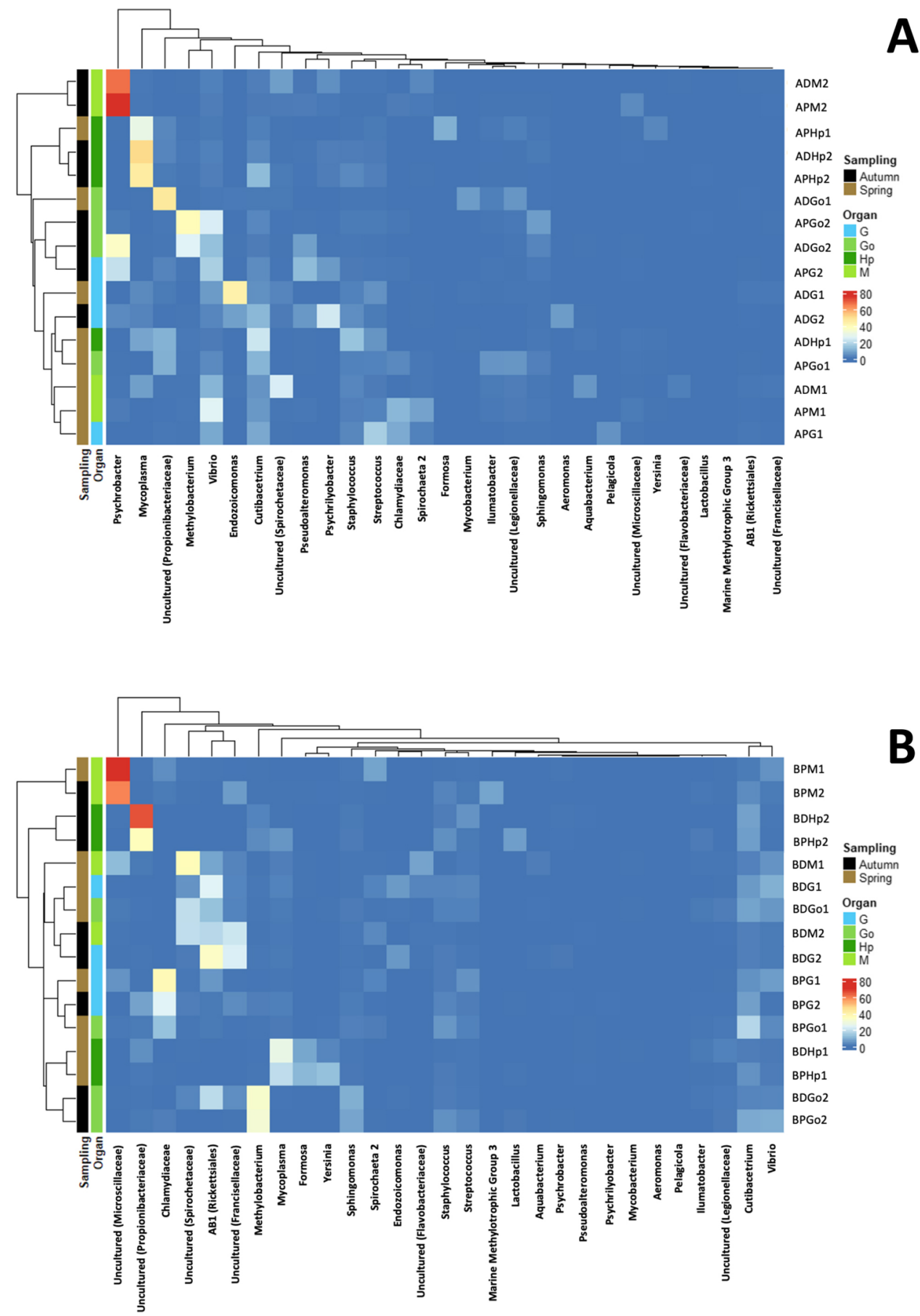

specimen variations. We found that each analysed tissue was composed, in terms of taxonomical composition and structure, of distinct bacterial communities. Besides, microbiota composition fluctuated between sampling periods.

Host-associated microbiota consist of more or less complex communities of microorganisms, some of which are more adapted to their host, other generalists or transient, representing a wide range of potential contributions (Shapira 2017). They play a key role in host homeostasis and health, by promoting development (McFall-Ngai 2002), providing protection against pathogens (Offret et al. 2018) or improving adaptation to environmental changes (Torda et al. 2017). It is well known that bivalves harbour their own microbiota (as for other organisms), whose characteristics and functions are still poorly understood, but cannot be ignored (Desriac et al. 2014; Offret et al. 2019a, b).

Our study contributes to widen the knowledge about the clam-associated microbiota and, specially, the microbial 


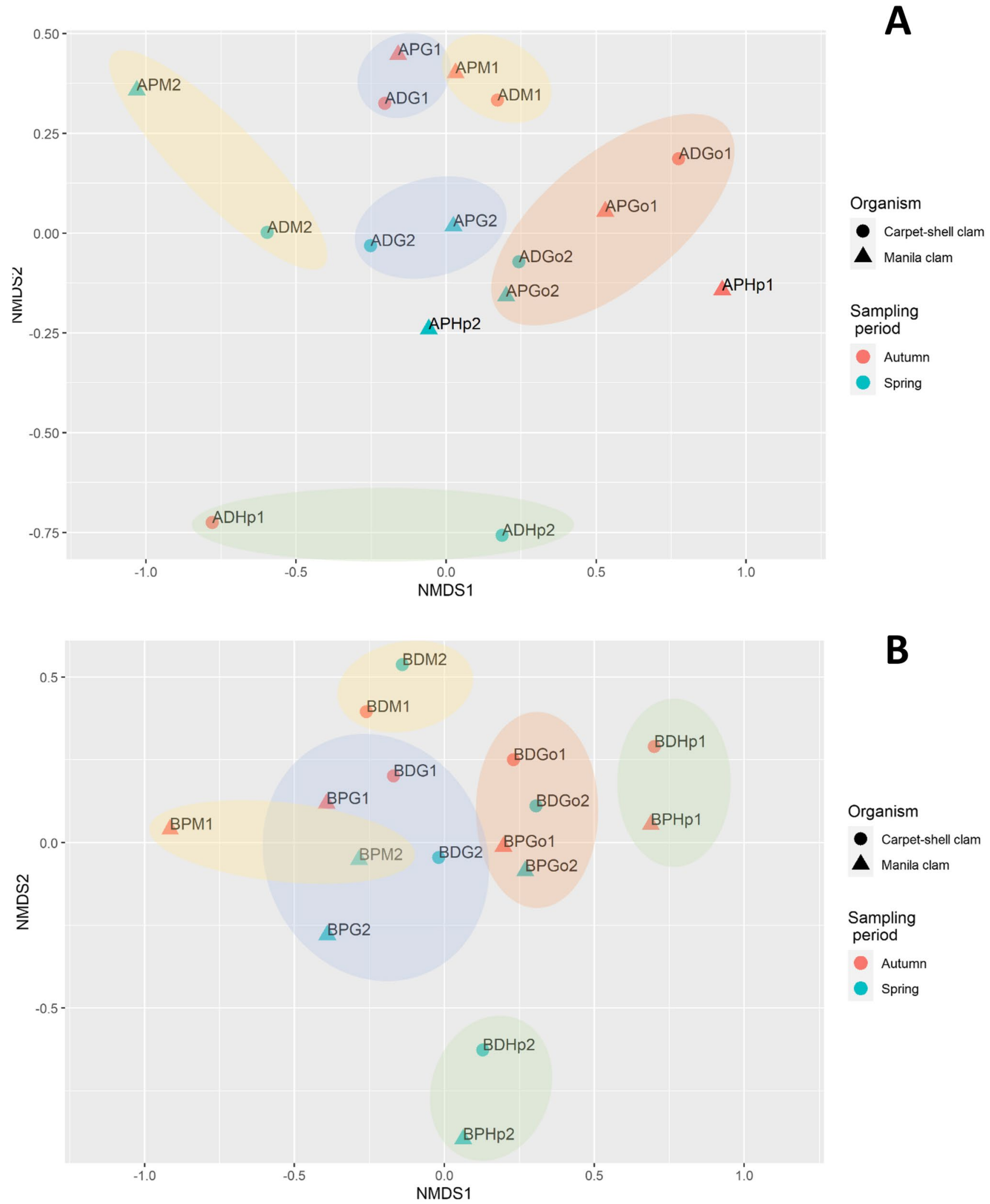

Fig. 6 2D representation of Nonmetric Multidimensional Scaling (NMDS) plots applied on ANOSIM distance matrix. Ellipses indicate group samples by tissue. A NDMS plot of site A. B NMDS plot of site B. A site A, B site B, D R. decussatus, P R. philippinarum, M mantle, G gills, Go gonads, Hp hepatopancreas, 1 April, 2 October 
structure population at the tissue level. We observed that the associated microbiota at tissue level consisted of a great bacterial diversity (Fig. 3) which, in origin, belonged to the marine environment, although host selection ultimately shaped the microbiota structure (Fig. 6A, B). Meisterhans et al. (2016) investigated Manila clamassociated microbiota at organ scale (gills, gut and a pool of remaining tissues), and they found that microbiota structure differed among organs indicating a selection of Manila clam microbiota at organ scale, which agrees with our results.

Despite variability across conditions, certain stability and specificity were observed in the different studied tissues, as we observed with Endozoicomonas, Methylobacterium, Mycoplasma, Psychrobacter or uncultured Propionibacteriaceae. The ecological role or potential symbiotic association of most of the bacterial groups identified and the host remains unclear; however, recent studies on marine symbionts have shed light into this question.

Endozoicomonas genus, mostly associated to gill samples in $R$. decussatus clams, has been associated as symbionts with a large diversity of marine organisms including cnidarians, poriferans, other molluscs, annelids, tunicates and fish (Neave et al. 2016). Despite the abundance of Endozoicomonas symbionts, only seven complete genomes are publically available, thus, limiting the understanding of their functional capacity. A comparative genomic study on Endozoicomonas (Neave et al. 2017) provided a deep functional insight into this genus. Genomic content showed an enrichment of genes associated with carbon sugar transport and utilization and protein secretion, potentially indicating that Endozoicomonas contribute to the cycling of carbohydrates and the provision of proteins to their respective hosts. Besides, Endozoicomonas genomes were enriched in transposition and DNA recombination systems, which may help the species to rapidly adapt to a new host or to opportunistically transition between symbiotic lifestyles (mutualistic, commensalistic or parasitic). Our results demonstrate that $R$. decussatus gills may represent an optimal environment for Endozoicomonas bacteria to survive in association with these clams by establishing complex interactions and providing a diversity of beneficial effects to the host.

Methylobacterium are facultative methylotrophic phytosymbionts that can utilize formaldehyde, methanol, methylamine or other methyl compounds, as sole carbon and energy source. Species of this genus have been often found associated to plants (they are able to produce phytohormones), mussels, soil or even extreme environments such as gamma ray-irradiated soil and a tungsten mine (Kim et al. 2019; Feng et al. 2020; Jia et al. 2020; Jiang et al. 2020); however, they have never been found before associated to clams. Their strong association to gonad samples suggests their potential implication in the protection of this particular organ or their ability to provide beneficial substances; however, these questions have not been addressed yet.

Recent studies have demonstrated that the bivalve microbiota is highly diverse and easily influenced by environmental factors, such as water temperature, $\mathrm{pH}$, salinity, dissolved oxygen, nutrients and infections (e.g. Green and Barnes 2010; Lokmer and Wegner 2015). Changes in the water temperature between sampling periods, as indicated above, might explain the variation in the relative abundances of the identified bacteria, that, indeed, is reflected in the hierarchical clustering (Fig. 5A,B) and the NMDS analysis (Fig. 6A,B). However, it remains unclear whether the compositional variation is due to the direct effect of water temperature in water microbial communities or as a result of the change on the physiology of R. decussatus and R. philippinarum clams, or both.

Clams from both sites harboured different bacterial communities associated to their organs. This result was expected since both habitats are geographically isolated one to each other, and, thus, different sediment conditions and trophic resources from which clams feed might be present. These aspects have a direct effect on both clam physiology and the bacterial suspension in the environment.

\section{Conclusions}

In light of our results, the microbial community structure of $R$. decussatus and $R$. philippinarum clams appears to be tissue dependent. Genera are shared across samples; however, differences in their relative abundances are significative, indicating that host selection of specific bacteria may occur. Seasonal changes and habitat influence are also observed in the bacterial composition, and, thus, these variables must be taken into account when analysing the health status of the clams.

Author contribution D.G. and A.L.: investigation, formal analysis and writing-original draft; A.L.: bioinformatic analysis; J.L.R., conceptualization, writing - review and editing, funding acquisition, supervision.

Funding Open Access funding provided thanks to the CRUECSIC agreement with Springer Nature. This work was supported in part by grant AGL2013-4268-R and AGL2016-77539-R from the Ministerio de Economía y Competitividad (Spain).

Data availability Sequence files for all samples used in this study have been deposited at NCBI SRA with accession: PRJNA428215.

Code availability Not applicable. 


\section{Declarations}

Ethics approval Not applicable.

Consent to participate Not applicable.

Consent for publication Not applicable.

Conflict of interest The authors declare no competing interests.

Open Access This article is licensed under a Creative Commons Attribution 4.0 International License, which permits use, sharing, adaptation, distribution and reproduction in any medium or format, as long as you give appropriate credit to the original author(s) and the source, provide a link to the Creative Commons licence, and indicate if changes were made. The images or other third party material in this article are included in the article's Creative Commons licence, unless indicated otherwise in a credit line to the material. If material is not included in the article's Creative Commons licence and your intended use is not permitted by statutory regulation or exceeds the permitted use, you will need to obtain permission directly from the copyright holder. To view a copy of this licence, visit http://creativecommons.org/licenses/by/4.0/.

\section{References}

Balboa S, Lasa A, Gerpe D, Diéguez AL, Romalde JL (2016) Microbiota associated to clams and oyster: a key factor for culture success. In: Romalde JL (ed) Oyster and Clams. Nova Science Publisher, New York, pp 39-66

Bolger AM, Lohse M, Usadel B (2014) Trimmomatic: a flexible trimmer for Illumina sequence data. Bioinformatics 30(15):21142120. https://doi.org/10.1093/bioinformatics/btu170

Bower SM, McGladdery SE, Price IM (1994) Synopsis of infectious disease and parasites of commercially exploited shellfish. Ann Rev Fish Dis 4(C):1-199. https://doi.org/10.1016/0959-8030(94) 90028-0

Clarke KR (1993) Non-parametric multivariate analyses of changes in community structure. Aust J Ecol 18(117):143. https://doi.org/10. 1111/j.1442-9993.1993.tb00438.x

Colwell RR, Liston J (1961) Taxonomic relationships among the pseudomonads. J Bacteriol 82(1):14

Colwell RR, Sparks AK (1967) Properties of Pseudomonas enalia, a marine bacterium pathogenic for the invertebrate Crassostrea gigas (Thunberg). Appl Microbiol 15(5):980-986

Desriac F, Le Chevalier P, Brillet B, Leguerinel I, Thuillier B, Paillard C, Fleury Y (2014) Exploring the hologenome concept in marine bivalvia: haemolymph microbiota as a pertinent source of probiotics for aquaculture. FEMS Microbiol Lett 350(1):107-16. https:// doi.org/10.1111/1574-6968.12308

Feng GD, Chen W, Zhang XJ, Zhang J, Wang SN, Zhu H (2020) Methylobacterium nonmethylotrophicum sp. nov., isolated from tungsten mine tailing. Int J Syst Evol Microbiol 70(4):2867-2872. https://doi.org/10.1099/ijsem.0.004112

Green TJ, Barnes AC (2010) Bacterial diversity of the digestive gland of Sydney rock oysters, Saccostrea glomerata infected with the paramyxean parasite Marteilia sydneyi. J Appl Microbiol 109(2):613-622. https://doi.org/10.1111/j.1365-2672.2010. 04687.x

Jia LJ, Zhang KS, Tang K, Meng JY, Zheng C, Feng FY (2020) Methylobacterium crusticola sp. nov., isolated from biological soil crusts. Int J Syst Evol Microbiol. 70(3):2089-2095. https://doi. org/10.1099/ijsem.0.004020
Jiang L, An D, Wang X, Zhang K, Li G, Lang L, Wang L, Jiang C, Jiang Y (2020) Methylobacterium planium sp. nov., isolated from a lichen sample. Arch Microbiol 202(7):1709-1715. https://doi. org/10.1007/s00203-020-01881-4

Kim J, Chhetri G, Kim I, Kim H, Kim MK, Seo T (2019) Methylobacterium terrae sp nov, a radiation-resistant bacterium isolated from gamma ray-irradiated soil. J Microbiol 57(11):959-966. https:// doi.org/10.1007/s12275-019-9007-9 (Erratum in: J Microbiol. 2020 58(1) 79)

King WL, Kaestli M, Siboni N, Padovan A, Christian K, Mills D, Seymour J, Gibb K (2021) Pearl oyster bacterial community structure is governed by location and tissue-type, but Vibrio species are shared among oyster tissues. Front Microbiol 12:723649. https:// doi.org/10.3389/fmicb.2021.723649

Kolde R (2015) URL https://CRAN.R-project.org/package=pheatmap. Accessed 6 July 2021

Lasa A, Mira A, Camelo-Castillo A, Belda-Ferre P, Romalde JL (2016) Characterization of the microbiota associated to Pecten maximus gonads using 454-pyrosequencing. Int Microbiol 19(2):93-99. https://doi.org/10.2436/20.1501.01.267

Lee CK, Barbier BA, Bottos EM, McDonald IR, Cary SC, Barbier BA (2012) The inter-valley soil comparative survey: the ecology of dry valley edaphic microbial communities. ISME J 6(1046):1057. https://doi.org/10.1038/ismej.2011.170

Leite L, Jude-Lemeilleur F, Raymond N, Henriques I, Garabetian F, Alves A (2017) Phylogenetic diversity and functional characterization of the Manila clam microbiota: a culture-based approach. Environ Sci Pollut Res Int 24(27):21721-21732. https://doi.org/10.1007/s11356-017-9838-z

Lokmer A, Wegner KM (2015) Hemolymph microbiome of Pacific oysters in response to temperature, temperature stress and infection. ISME J 9(3):670-682. https://doi.org/10.1038/ismej.2014. 160

Lokmer A, Kuenzel S, Baines JF, Wegner KM (2016) The role of tissue-specific microbiota in initial establishment success of Pacific oysters. Environ Microbiol 18(3):970-987. https://doi. org/10.1111/1462-2920.13163

Lovelace TE, Tubiash H, Colwell RR (1968) Quantitative and qualitative commensal bacterial flora of Crassostrea virginica in Chesapeake Bay. Proc Natl Shellfish Assoc 58(82):87

Mandel MJ, Dunn AK (2016) Impact and influence of the natural Vibrio-squid symbiosis in understanding bacterial-animal interactions. Front Microbiol 7:1982

McFall-Ngai MJ (2002) Unseen forces: the influence of bacteria on animal development. Dev Biol 242(1):14

McHenery JG, Birkbeck TH (1985) Uptake and processing of cultured microorganisms by bivalves. J Exp Mar Biol Ecol 90(2):145-163. https://doi.org/10.1016/0022-0981(85)90116-9

Meisterhans G, Raymond N, Girault E, Lambert C, Bourrasseau L, de Montaudouin X, Garabetian F, Jude-Lemeilleur F (2016) Structure of Manila clam (Ruditapes philippinarum) microbiota at the organ scale in contrasting sets of individuals. Microb Ecol 71(1):194-206. https://doi.org/10.1007/s00248-015-0662-z

Neave MJ, Apprill A, Ferrier-Pagès C, Voolstra CR (2016) Diversity and function of prevalent symbiotic marine bacteria in the genus Endozoicomonas. Appl Microbiol Biotechnol 100(19):83158324. https://doi.org/10.1007/s00253-016-7777-0

Neave MJ, Michell CT, Apprill A, Voolstra CR (2017) Endozoicomonas genomes reveal functional adaptation and plasticity in bacterial strains symbiotically associated with diverse marine hosts. Sci Rep 17(7):40579. https://doi.org/10.1038/srep40579

Offret C, Rochard V, Laguerre H et al (2019a) Protective efficacy of a Pseudoalteromonas strain in European Abalone, Haliotis tuberculata, infected with Vibrio harveyi ORM4. Probiotics \& Antimicro Prot 11(239):247. https://doi.org/10.1007/s12602-018-9389-8 
Offret C, Jégou C, Mounier J, Fleury Y, Le Chevalier P (2019) New insights into the haemo- and coelo-microbiota with antimicrobial activities from Echinodermata and Mollusca. J Appl Microbiol 26(4):1023-1031. https://doi.org/10.1111/jam.14184

Oksanen JF, Blanchet G, Friendly F, Kindt R, Legendre P, McGlinn D, Minchin PR, O'Hara RB, Simpson GL, Solymos P, Stevens MHH, Szoecs E, Wagner E (2017) vegan: community ecology package. $\mathrm{R}$ package version 2.4-5. https://CRAN.R-project.org/package $=$ vegan. Accessed 6 July 2021

Paillard C, Le Roux F, Borrego JJ (2004) Bacterial disease in marine bivalves, a review of recent studies: trends and evolution. Aquat Living Resour 17(477):498. https://doi.org/10.1051/alr:2004054

Prieur D, Mével G, Nicolas JL, Plusquellec A, Vigneulle M (1990) Interactions between bivalve molluscs and bacteria in the marine environment. Oceanogr Mar Biol Annu Rev 28(277):352

Pujalte MJ, Ortigosa M, Macián MC, Garay E (1999) Aerobic and facultative anaerobic heterotrophic bacteria associated to Mediterranean oysters and seawater. Int Microbiol 2(4):259-266

Quast C, Pruesse E, Yilmaz P, Gerken J, Schweer T, Yarza P, Glöckner FO (2013) The SILVA ribosomal RNA gene database project: improved data processing and web-based tools. Nucleic Acids Res 41:D1. https://doi.org/10.1093/nar/gks1219

Rajagolapan LPD, Sivalingan PM (1978) Bacteria flora of a great mussel (Mytilus viridis Linnaeus) and naturally occurring rock oyster (Crassostreae cuculata). Mar Appl Biol 7(43):47

Romalde JL, Diéguez AL, Doce A, Lasa A, Balboa S, López C, BeazHidalgo R (2013) Advances in the knowledge of the microbiota associated with clams from natural beds. In: da Costa F (ed) Clam fisheries and aquaculture. Nova Science Publishers, New York, pp 163-190

Romalde JL, Diéguez AL, Lasa A, Balboa S (2014) New Vibrio species associated to molluscan microbiota: a review. Front Microbiol 4:413. https://doi.org/10.3389/fmicb.2013.00413

Romanenko LA, Uchino M, Kalinovskaya NI, Mikhailov VV (2008) Isolation, phylogenetic analysis and screening of marine mollusc-associated bacteria for antimicrobial, hemolytic and surface activities. Microbiol Res 163(633):644. https://doi.org/10.1016/j. micres.2006.10.001
Roterman YR, Benayahu Y, Reshef L, Gophna U (2015) The gill microbiota of invasive and indigenous Spondylus oysters from the Mediterranean Sea and northern Red Sea. Environ Microbiol Rep 7(6):860-867. https://doi.org/10.1111/1758-2229.12315

Seguineau C, Laschi-Loquerie A, Moal J, Samain JF (1996) Vitamin requirements in great scallop larvae. Aquacult Int 4(4):315-324. https://doi.org/10.1007/bf00120948

Shapira M (2017) Host-microbiota interactions in Caenorhabditis elegans and their significance. Curr Opin Microbiol 38:142-147. https://doi.org/10.1016/j.mib.2017.05.012

Singh BK, Liu H, Trivedi P (2020) Eco-holobiont: a new concept to identify drivers of host associated microorganisms. Environ Microbiol 22(564):567

Torda G, Donelson J, Aranda M et al (2017) Rapid adaptive responses to climate change in corals. Nature Clim Change 7(627):636. https://doi.org/10.1038/nclimate3374

Trabal Fernández N, Mazón-Suástegui JM, Vázquez-Juárez R, Ascencio-Valle F, Romero J (2014) Changes in the composition and diversity of the bacterial microbiota associated with oysters (Crassostrea corteziensis, Crassostrea gigas and Crassostrea sikamea) during commercial production. FEMS Microbiol Ecol 88(1):6983. https://doi.org/10.1111/1574-6941.12270

Vezzulli L, Stagnaro L, Grande C, Tassistro G, Canesi L, Pruzzo C (2017) Comparative 16SrDNA gene-based microbiota profiles of the Pacific oyster (Crassostrea gigas) and the Mediterranean mussel (Mytilus galloprovincialis) from a shellfish farm (Ligurian Sea, Italy). Microb Ecol 75(495):504. https://doi.org/10.1007/ s00248-017-1051-6

Yu J, Wang M, Liu B, Yue X, Li C (2019) Gill symbionts of the coldseep mussel Bathymodiolus platifrons: composition, environmental dependency and immune control. Fish Shellfish Immunol 86(246):252

Publisher's note Springer Nature remains neutral with regard to jurisdictional claims in published maps and institutional affiliations. 